\title{
Imatinib-Induced Tremor in a Patient with Chronic Myeloid Leukemia in Chronic Phase
}

\author{
Khaldun Obeidat $^{a} \quad$ Arwa Alsaud $^{a} \quad$ Amr Ashour $^{a} \quad$ Bahjat Azrieh $^{a}$ \\ Mohammad Abu-Tineh $^{\mathrm{a}}$ Shehab Fareed Mohamed ${ }^{\mathrm{b}}$ \\ Mohamed A. Yassin ${ }^{b}$ \\ aDepartment of Medical Education, Hamad Medical Corporation, Doha, Qatar; \\ ${ }^{b}$ Department of Medical Education, Hamad Medical Corporation, Department of Medical \\ Oncology, NCCCR, Hamad Medical Corporation, Doha, Qatar
}

\section{Keywords}

Chronic myeloid leukemia · Imatinib · Side effects · Tremor · Tyrosine kinases

\section{Abstract}

Chronic myeloid leukemia (CML) is a myeloproliferative neoplasm characterized by three phases: chronic, accelerated, and blast phase. However; first- and second-generation tyrosine kinase inhibitors are used for the treatment of CML with common and uncommon adverse events. Here, we report a 24-year-old male with CML in chronic phase started on imatinib as upfront medication who developed tremor and recovered spontenously after 3 years.

\section{Background}

Chronic myeloid leukemia (CML) accounts for approximately $15-20 \%$ of all leukemias in adults [1]. It has an annual incidence of 1-2 cases per 100,000, with a slight male predominance [2-4]. The median age at presentation is approximately 50 years.

CML is a myeloproliferative neoplasm characterized by the uncontrolled production of mature and maturing granulocytes with normal differentiation, and it is associated with the fusion of two genes: $B C R$ (on chromosome 22) and $A B L 1$ (on chromosome 9) resulting in the $B C R-A B L 1$ fusion gene which gives rise to an abnormal chromosome 22, called the Philadelphia $(\mathrm{Ph})$ chromosome. The $\mathrm{Ph}$ chromosome results in the formation of a unique gene 
product, the BCR-ABL1 fusion protein. Its product includes an enzymatic domain from the normal ABL1 with tyrosine kinase catalytic activity, and this deregulates tyrosine kinase that is implicated in the pathogenesis of CML.

The initial treatment of Ph-positive $(\mathrm{Ph}+), \mathrm{BCR}-\mathrm{ABL}+\mathrm{CML}$ is based on tyrosine kinase inhibitors (TKI) [5]. The first goal of treatment is to prevent progression, the second goal is to eliminate the leukemic clone.

Several TKIs are able to inhibit the BCR-ABL proteins. The TKIs registered so far for their activity on BCR-ABL include imatinib (Glivec or Gleevec, Novartis Pharma) [6, 7], Nilotinib (Tasigna, Novartis Pharma) [6, 8], and Dasatinib (Sprycel, Bristol-Myers Squibb) [6, 9].

There is a wide range of side effects for imatinib which have been reported by the manufacturing company "Novartis." It can affect almost every organ in the body. Here, we present a case with a rare side effect of imatinib, tremor.

\section{Case}

A 24-year-old Nepalese man, previously healthy, was diagnosed with CML in 2013. He presented at that time to the Emergency Unit with fever and itching. He was found to have a high white blood cell count of 132,000 (normal range: 4,000-10,000) with peripheral smear suggestive of CML. His clinical examination was not remarkable. Bone marrow aspiration and biopsy were done with cytogenetic molecular testing to confirm the diagnosis. The patient was positive for BCR-ABL.

The diagnosis of CML was confirmed, and the patient was started on imatinib $400 \mathrm{mg}$ p.o. once daily in November 2013. He was tolerating imatinib very well and achieved complete hematologic and cytogenetic response. The patient was followed and treated according to the European Leukemia Net Recommendations for CML. The patient was still on imatinib $400 \mathrm{mg}$ every other day in 2016. During a routine follow-up in the clinic, the clinical examination revealed a fine tremor. There were no signs or symptoms of hyperthyroidism.

While analyzing the patient's history regarding his tremor, he denied a family history, alcohol consumption, or the use of other medications.

\section{Discussion}

Imatinib is a TKI approved for several different conditions which include [10]: newly diagnosed adult and pediatric patients with $\mathrm{Ph}+\mathrm{CML}$ in the chronic phase; patients with $\mathrm{Ph}$ + CML in blast crisis, accelerated phase, or in the chronic phase after failure of interferon- $\alpha$ therapy; adult patients with relapsed or refractory $\mathrm{Ph}+$ acute lymphoblastic leukemia $(\mathrm{Ph}+$ ALL); pediatric patients with newly diagnosed Ph+ ALL in combination with chemotherapy; adult patients with myelodysplastic/myeloproliferative diseases associated with PDGFR (platelet-derived growth factor receptor) gene rearrangements as determined by an FDAapproved test; adult patients with aggressive systemic mastocytosis without a D816V c-KIT mutation as determined by an FDA-approved test or with c-KIT mutational status unknown; adult patients with hypereosinophilic syndrome (HES) and/or chronic eosinophilic leukemia (CEL) who have a FIP1L1-PDGFR $\alpha$ fusion kinase and for patients with HES and/or CEL who are FIP1L1-PDGFR $\alpha$ fusion kinase negative or where the status is unknown; adult patients with unrespectable, recurrent, and/or metastatic dermatofibrosarcoma protuberans; patients with KIT (CD117)-positive gastrointestinal stromal tumors (GIST) that cannot be surgically removed and/or have spread to other parts of the body; and adult patients after surgery who have had their KIT (CD117)-positive GIST completely removed. 
Obeidat et al.: Imatinib-Induced Tremor in a Patient with Chronic Myeloid Leukemia in Chronic Phase

With imatinib, the complete hematologic response rate is close to $100 \%$, the complete cytogenetic response $(\mathrm{CCgR})$ rate ranges between 65 and $80 \%$, the major molecular response rate (or BCR-ABL $\leq 0.1 \%$ on the International Scale) ranges between 40 and $60 \%$, and the complete molecular response rate (or BCR-ABL $\leq 0.01 \%$ on the International Scale) ranges between 15 and $30 \%$ [7, 11-15]. About $20 \%$ of all patients become resistant, about $15 \%$ of all patients discontinue imatinib because of side effects.

There is a wide range of side effects for imatinib which have been reported by the manufacturing company "Novartis." It can affect almost every organ in the body, and tremor is mentioned under nervous system disorders which are classified according to their frequency and include: the very common category $(\geq 10 \%)$ includes headache $(37 \%)$ and dizziness (19\%); the common category (1-10\%) includes paresthesia and hypoesthesia; the uncommon category $(0.1-1 \%)$ includes migraine, syncope, peripheral neuropathy, sciatica, restless leg syndrome, tremor, and vertigo; and the rare category $(<0.1 \%)$ includes seizures.

Since our patient was diagnosed with CML in 2013, he was initiated on imatinib $400 \mathrm{mg}$ once daily. He was followed up regularly in an outpatient clinic including physical exam and laboratory. He did not experience any of the above-mentioned side effects.

Tremor was reported previously in two cases of GIST; the first one was published in 2011 on a patient who was diagnosed with GIST at the age of 74 and who was started on imatinib in 2001. He was treated for 10 years. He experiences one of the mentioned side effects: intention tremor [16]. The second case was published in 2015 about a 74-year-old female who was diagnosed with GIST and received imatinib mesylate as adjuvant therapy after surgical resection [17]. According to our knowledge tremor has not been reported before in CML patients.

When we observed this side effect in our patient, we first excluded other causes by analyzing his family history in detail, medication, and herbal usage. Physical exam did not reveal any abnormalities other than fine tremor (intentional). Tests of renal function, liver function, and thyroid function were normal. ECG was also normal.

In general, most of the side effects happen during the first 2 years of treatment, and some are reversible without changing the dosage [18]. Since our patient's tremor is mild and the current dosage achieved complete remission, we decide to continue with the same dosage.

\section{Conclusion}

Although tremor is reported as one of the rare side effects of imatinib by the pharmaceutical company, it has not been reported much in the literature, and it might be overlooked by physicians. Tremor might cause suffering to affected individuals and disturb their quality of life. We would like to highlight this rare side effect in order to increase physician awareness for a better education and reassurance to their patients.

\section{Acknowledgement}

We thank Qatar national library for funding this article, and we thank the internal medicine residency program research group at Hamad Medical Corporation. 
Obeidat et al.: Imatinib-Induced Tremor in a Patient with Chronic Myeloid Leukemia in Chronic Phase

\section{Statement of Ethics}

This case report was approved by the Hamad Medical Corporation medical research center and the Institutional Review Board. As per the Hamad Medical Corporation medical research center, the need for informed consent was waived for this case report unless it contains identifiers or images.

\section{Disclosure Statement}

The authors have nothing to disclose.

\section{Funding Sources}

This article was funded by Qatar national library.

\section{Author Contributions}

Khaldun Obeidat: writing the manuscript. Arwa Alsaud, Amr Ashour, Bahjat Azrieh, Mohammad Abu-Tineh, and Shehab Fareed Mohammad: clinical management. Mohamed A. Yassin: writing and editing.

\section{References}

1 Siegel RL, Miller KD, Jemal A. Cancer statistics, 2017. CA Cancer J Clin. 2017 Jan;67(1):7-30.

2 Sant M, Allemani C, Tereanu C, De Angelis R, Capocaccia R, Visser O, HAEMACARE Working Group. Incidence of hematologic malignancies in Europe by morphologic subtype: results of the HAEMACARE project. Blood. 2010 Nov; 116(19):3724-34.

3 Smith A, Howell D, Patmore R, Jack A, Roman E. Incidence of haematological malignancy by sub-type: a report from the haematological malignancy research network. Br J Cancer. 2011 Nov;105(11):1684-92.

4 Chen Y, Wang H, Kantarjian H, Cortes J. Trends in chronic myeloid leukemia incidence and survival in the United States from 1975 to 2009. Leuk Lymphoma. 2013 Jul;54(7):1411-7.

5 Hehlmann R, Hochhaus A, Baccarani M,, European LeukemiaNet. Chronic myeloid leukaemia. Lancet. 2007 Jul; 370(9584):342-50.

6 Quintás-Cardama A, Cortes J. Molecular biology of bcr-abl1-positive chronic myeloid leukemia. Blood 2009 Feb; 113(8):1619-30.

7 O’Brien SG, Guilhot F, Larson RA, Gathmann I, Baccarani M, Cervantes F. Imatinib compared with interferon and low-dose cytarabine for newly diagnosed chronic-phase chronic myeloid leukemia. N Engl J Med. 2003 Mar;348(11):994-1004.

8 Kantarjian HM, Giles FJ, Bhalla KN, Pinilla-Ibarz J, Larson RA, Gattermann N. Nilotinib is effective in patients with chronic myeloid leukemia in chronic phase after imatinib resistance or intolerance: 24-month follow-up results. Blood. 2011 Jan;117(4):1141-5.

9 Hochhaus A, Kantarjian HM, Baccarani M, Lipton JH, Apperley JF, Druker BJ. Dasatinib induces notable hematologic and cytogenetic responses in chronic-phase chronic myeloid leukemia after failure of imatinib therapy. Blood. 2007 Mar;109(6):2303-9.

10 Imatinib. www.us.gleevec.com.

11 Hughes TP, Kaeda J, Branford S, Rudzki Z, Hochhaus A, Hensley ML. Frequency of major molecular responses to imatinib or interferon alfa plus cytarabine in newly diagnosed chronic myeloid leukemia. N Engl J Med. 2003 Oct;349(15):1423-32.

12 Druker BJ, Guilhot F, O’Brien SG, Gathmann I, Kantarjian H, Gattermann N. Five-year follow-up of patients receiving imatinib for chronic myeloid leukemia. N Engl J Med. 2006 Dec;355(23):2408-17.

13 Hochhaus A, O'Brien SG, Guilhot F, Druker BJ, Branford S, Foroni L. Six-year follow-up of patients receiving imatinib for the first-line treatment of chronic myeloid leukemia. Leukemia. 2009 Jun;23(6):1054-61. 
14 Baccarani M, Rosti G, Castagnetti F, Haznedaroglu I, Porkka K, Abruzzese E. Comparison of imatinib 400 mg and $800 \mathrm{mg}$ daily in the front-line treatment of high-risk, Philadelphia-positive chronic myeloid leukemia: a European LeukemiaNet Study. Blood. 2009 May;113(19):4497-504.

15 Hehlmann R, Lauseker M, Jung-Munkwitz S, Leitner A, Müller MC, Pletsch N. Tolerability-adapted imatinib $800 \mathrm{mg} / \mathrm{d}$ versus $400 \mathrm{mg} / \mathrm{d}$ versus $400 \mathrm{mg} / \mathrm{d}$ plus interferon- $\alpha$ in newly diagnosed chronic myeloid leukemia. J Clin Oncol. 2011 Apr;29(12):1634-42.

16 Cameron S, Schaefer IM, Schwoerer H, Ramadori G. Ten years of treatment with $400 \mathrm{mg}$ imatinib per day in a case of advanced gastrointestinal stromal tumor. Case Rep Oncol. 2011 Sep;4(3):505-11.

17 Jang BH, Kim BW, Lim KJ, Kim BG, Park SM, Kim JS. A case of disseminated intra-abdominal gastrointestinal stromal tumor managed with low dose imatinib. Korean J Gastroenterol. 2015 Jun;65(6):366-9.

18 Mughal TI, Schrieber A. Principal long-term adverse effects of imatinib in patients with chronic myeloid leukemia in chronic phase. Biologics. 2010 Dec:4:315-23. 